\title{
Investigation into the energy consumption of a data center with a thermosyphon heat exchanger
}

\author{
ZHOU Feng, TIAN Xin \& MA GuoYuan* \\ College of Environmental and Energy Engineering, Beijing University of Technology, Beijing 100124, China
}

Received October 18, 2010; accepted February 17, 2011

\begin{abstract}
A data center test model was used to analyze the energy dissipation characteristics and energy consumption of a data center. The results indicate that adequate heat dissipation from a data center cannot be achieved only from heat dissipation through the building envelope during Beijing winter conditions. This is because heat dissipation through the building envelope covers about $19.5 \%$ of the total data center heat load. The average energy consumption for an air conditioner is 4 to $5 \mathrm{~kW}$ over a 24 -h period. The temperature difference between the indoor and outdoor air for the data center with a thermosyphon heat exchanger is less than $20^{\circ} \mathrm{C}$. The energy consumption of the thermosyphon heat exchanger is only $41 \%$ of that of an air conditioner. The annual energy consumption can be reduced by $35.4 \%$ with a thermosyphon system. In addition, the effect of the outdoor temperature on the energy consumption of an air conditioner is greater than the indoor room temperature. The energy consumption of an air conditioner system increases by $5 \%$ to $6 \%$ for every $1{ }^{\circ} \mathrm{C}$ rise in the outdoor temperature.
\end{abstract}

data center, energy consumption, thermosyphon heat exchanger, ambient energy

Citation: Zhou F, Tian X, Ma G Y. Investigation into the energy consumption of a data center with a thermosyphon heat exchanger. Chinese Sci Bull, 2011, 56: 2185-2190, doi: 10.1007/s11434-011-4500-5

The energy consumption of data centers has increased rapidly in recent years, and the situation is getting worse. The US Environmental Protection Agency (EPA) estimates that the total energy cost for all data centers in the US in 2006 was 4.5 billion dollars, and the cost will reach 7.4 billion dollars by 2011 [1]. In addition, the power consumption of servers is increasing rapidly. In 1998 the thermal load for a dense rack-mount server was about $5 \mathrm{~kW}$ per rack and in 2006 it increased to $32 \mathrm{~kW}$ per rack. According to predictions of the American Society of Heating, Refrigeration and Air-Conditioning Engineers (ASHRAE), the thermal load will reach $42 \mathrm{~kW}$ per rack by 2014 [2]. The cooling and the auxiliary equipment power consumptions are increasing rapidly with a sharp increase in the number and power of servers, which in turn rapidly increases the energy consumption.

According to an investigation by the Lawrence Berkeley

*Corresponding author (email: magy@bjut.edu.cn)
National Laboratory, the energy consumption of a typical data center is made up of $44 \%$ from IT devices (including servers, switches and routers), 38\% from cooling devices (including air conditioners and fans), 15\% from power devices (including Uninterrupted Power Supplies (UPS) and Server Power Management (SPM) equipment), and 3\% from lights. The energy consumption of the cooling equipment is second only to that of the IT equipment.

In response to this growing energy problem, all data centers have adopted new techniques to improve their energy efficiency [3], with most including accurate temperature control and air flow management of the air conditioning system [4-6]. In addition, $10 \%$ of data centers have air cooled or water cooled equipment which can use natural circulation to effectively cool the data center for free and thus reduce the energy consumption of the cooling equipment [7]. In ASHRAE Standard 90, naturally cooled equipment is required in some zones in the US, especially in the western and northeastern zones with cooler weather. 
Current investigations into ambient energy for cooling data centers have mainly considered air ventilation cooling, including direct fresh air cooling systems [8-11], and separated fresh air heat exchangers [12], which include aluminum plate heat exchangers and thermosyphon heat exchangers. However, the performance of direct fresh air cooling systems, which are suitable for cool zones with high quality air, varies by location [13]. The actual temperature efficiency of plate heat exchangers, which is limited by the structure and the heat transfer mode, is not high. Thermosyphon heat exchangers can provide more efficient cooling over larger areas. Thermosyphon heat exchangers have been proposed for cooling data centers [14], but specific investigations are still needed including analysis of the heat dissipation through the building envelope and the energy consumption of the data centers using thermosyphon heat exchangers.

Consequently a thermosyphon heat exchanger was built to use ambient energy to cool a typical data center. The heat dissipation characteristics and the energy consumption of the thermosyphon heat exchanger and the equivalent air conditioner system were then studied during a Beijing winter. The heat flux through the building envelope was measured to confirm calculations of the data center heat dissipation through the building envelope. In addition, the effects of different indoor set temperatures and different outdoor temperatures on the total air conditioner energy consumption were also analyzed.

\section{Experimental systems and instrumentation}

Figure 1(a) shows an actual data center in Beijing with telecommunication cabinets, air conditioners, batteries, and switch powers supplies. The data center test model in Figure 1(b) was set up with the equipment in the same locations as the actual data center. The temperatures and heat fluxes were measured from November 15, 2009 to January 18, 2010 during the Beijing winter. A polystyrene sandwich panel (Type 950) used as the wall material had a total

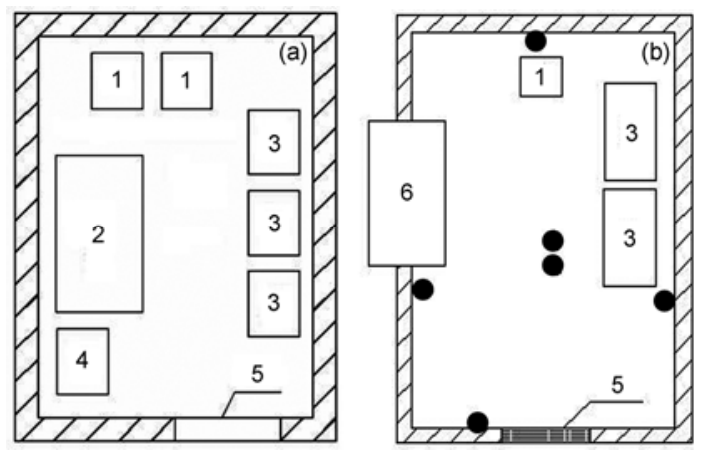

Figure 1 Distribution of data center equipment and heat flux meters. 1 , Air conditioner; 2 , battery; 3 , telecommunication cabinets; 4 , switch power supply; 5 , door; 6 , thermosyphon heat exchanger; $\bullet$, heat flux meter. thickness of $100 \mathrm{~mm}$ with $0.8 \mathrm{~mm}$ double-faced steel panels and a $18 \mathrm{~kg} / \mathrm{m}^{3}$ bulk weight core.

A $1.1 \mathrm{~kW}$ electric heater with a fan was used to simulate the telecommunication cabinets. The hot air from the electric module flowed through an air duct from the fan according to the air flow direction of the actual telecommunication cabinets. A thermosyphon heat exchanger, which used ambient energy to cool the data center, was installed with a rated heat dissipation capacity of $2 \mathrm{~kW}$. The unit was 750 $\mathrm{mm} \times 320 \mathrm{~mm} \times 290 \mathrm{~mm}$. The thermosyphon heat exchanger had two separate parts with a partition in the middle. The thermosyphon core was made of standard copper tubing containing the working fluid. The thermosyphon heat exchanger was inclined from the horizontal. Fans were installed in both the indoor and outdoor air ducts with a total rated fan power of $60 \mathrm{~W}$. The air conditioner in the model data center was a Media Type KFR-32GW/Y unit with a rated refrigeration capacity of $3.2 \mathrm{~kW}$ and a rated power of $1.19 \mathrm{~kW}$, and was chosen to match the actual data center.

The heat fluxes, temperatures and active power were measured during the experiments. The heat dissipation through the building envelope was calculated based on the heat fluxes. The heat fluxes were measured using the Beijing Shi Ji Jian Tong Type JTRG-II Building Thermal Temperature \& Heat Flux Auto Test System. The heat flux data were recorded each minute with heat flux meters on each of the six surfaces as shown in Figure 1. The measurement accuracy was 5\%o and the resolution of the heat flux meter was $0.1 \mathrm{~W} / \mathrm{m}^{2}$. The wall positions of the heat flux meters were chosen with a Testo Type 880 Thermal Infrared Imager. The energy consumption of the air conditioner was measured based on the active power consumed by the air conditioner $\mathrm{P}$ in $\mathrm{kW}$. The active power was measured each minute using a LEM Type ANALYST 3P Power Quality Analyser. The resolutions were $0.1 \mathrm{~V}$ for voltage and $0.01 \mathrm{~A}$ for current. The operating errors were $0.5 \%$ for voltage and $1 \%$ for current. The temperatures were measured at six points covering the indoor and outdoor room temperatures and the thermosyphon heat exchanger inlet and outlet air temperatures. The temperatures were measured using a YOKOGAWA Type DX 230-1-2 DAQ STATION every $2 \mathrm{~s}$ with Type T $2 \times 0.3 \mathrm{~mm}$ calibrated thermocouples.

\section{Results and discussion}

\subsection{Base room temperature}

If there was no cooling equipment in the data center, the heat would all be dissipated through the building envelope. The indoor temperature measured in this condition is called the base room temperature $\left(T_{\mathrm{B}}\right)$. To get a quantitative understanding, the base room temperature was measured as a function of the outdoor temperature from 16:47, Jan. 13, 2010 to $16: 47$, Jan. 14,2010 . The temperature variations 
obtained in this 24-h period are shown in Figure 2.

During this period, the energy was only dissipated through the building envelope with no auxiliary cooling. As shown in Figure 2, the base room temperature changed as the outdoor temperature varied, increasing as the outdoor temperature increased and decreasing as the outdoor temperature decreased. Throughout this time, however, the temperature difference between the indoor and outdoor temperatures remained almost constant.

Even though the outdoor temperature was below $0^{\circ} \mathrm{C}$ during the testing period for these typical winter conditions, the base room temperature was still more than $30^{\circ} \mathrm{C}$. The average base room temperature was $32.7^{\circ} \mathrm{C}$ with the highest being $37.8^{\circ} \mathrm{C}$. The temperature difference between the inside and outside temperatures was over $30^{\circ} \mathrm{C}$. Therefore, the heat transfer through the building envelope could not dissipate all the heat input to the room on cold winter days.

\subsection{Air conditioner power consumption}

In the second set of tests, the air conditioner was turned on with the temperature set at $25^{\circ} \mathrm{C}$. The thermal dissipation characteristics and the energy consumption were then measured over a continuous 48 hour period from 20:51, Nov. 15, 2009 to $20: 51$, Nov. 17, 2009. The variations in the indoor and outdoor temperatures and the energy dissipation through the building envelope during these tests are shown in Figure 3.

The indoor temperature was kept constant at $25^{\circ} \mathrm{C}$, while the outdoor temperature changed as shown in Figure 3. The heat dissipation through the building envelope was in the range 180-250 W with an average thermal dissipation of $214 \mathrm{~W}$, which is about $19.5 \%$ of the total $1.1 \mathrm{~kW}$ heat load. The variation in power consumption of the air conditioner, as shown in Figure 4, varied greatly as the air conditioner cycled on and off to maintain a constant indoor temperature. The total power consumption of the air conditioner over the 48 -h period was $7.074 \mathrm{~kW}$. Thus, the air conditioner energy consumption averaged $3.5 \mathrm{~kW}$ over $24 \mathrm{~h}$.

\subsection{Ambient energy cooling}

The telecommunication equipment in a data center is nor-

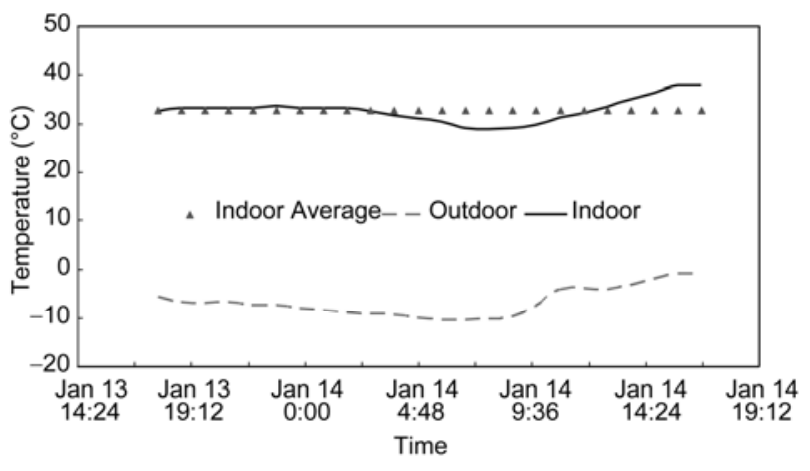

Figure 2 Base room temperature in the data center.

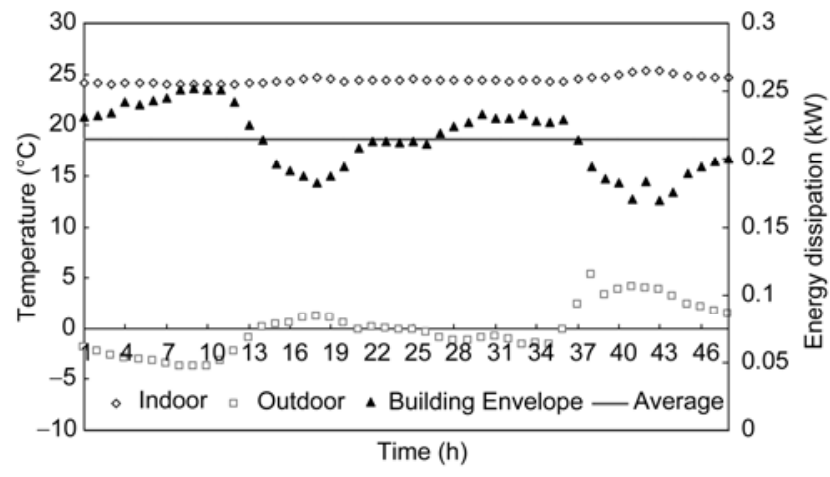

Figure 3 Indoor and outdoor temperatures and energy dissipation through the building envelope.

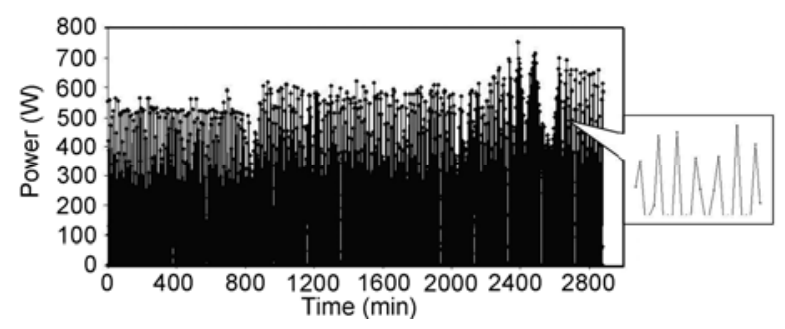

Figuer 4 An air conditioner power consumption.

mally always on. The cooling system has to operate throughout the year in some areas, which consumes much energy. Using ambient energy (outdoor cool air) to cool the data center will shorten the air conditioner running time and reduce the energy consumption. The DeST software for building energy consumption analysis developed by Tsinghua University was used to model the data center. The model neglected the center's personnel thermal load, the lighting load, and the cooling leakage while the door was open. The indoor temperature was set at $18-25^{\circ} \mathrm{C}$ with relative humidity of $40 \%-70 \%$. The start-up temperature difference of the thermosyphon heat exchanger was set to $3^{\circ} \mathrm{C}$. The simulation results showed that the thermosyphon heat exchanger reduced the annual energy consumption by around $47 \%$ in Beijing.

A thermosyphon heat exchanger was then installed in the test model data center. The energy dissipation characteristics of the thermosyphon heat exchanger were then studied for $47 \mathrm{~h}$ from 22:47, Jan. 16, 2010 to 21:47, Jan. 18, 2010. The indoor and outdoor temperatures and the difference between the indoor and outdoor temperatures with the thermosyphon heat exchanger are shown in Figure 5.

The indoor temperature changes with respect to the outdoor temperature as shown in Figure 5. The outdoor temperature affects the thermal dissipation through the building envelope with lower outdoor temperatures resulting in more heat dissipation through the building envelope. The energy dissipation from the thermosyphon heat exchanger also changes with the outdoor temperature [15]. Thus, lower outdoor temperatures result in more energy dissipation 


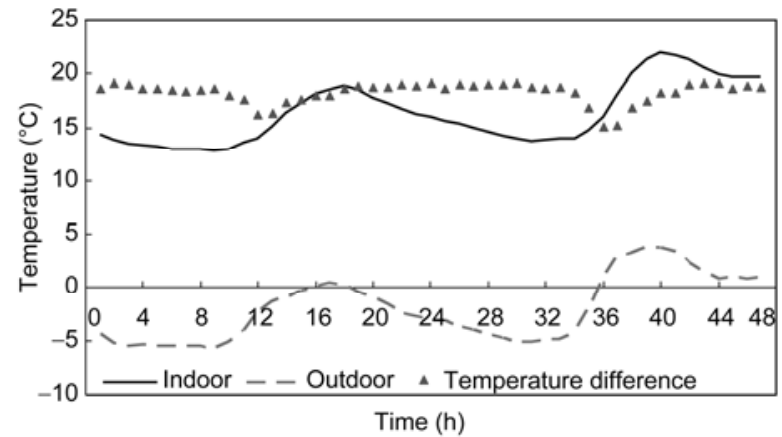

Figure 5 Indoor and outdoor temperatures with the thermosyphon heat exchanger.

from the thermosyphon heat exchanger. Figure 5 shows that the outdoor temperature in this period ranged from $-5.8^{\circ} \mathrm{C}$ to $3.8^{\circ} \mathrm{C}$, while the indoor temperature ranged from $12.8^{\circ} \mathrm{C}$ to $21.9^{\circ} \mathrm{C}$, which is less than $22^{\circ} \mathrm{C}$ and much less than the $26.7^{\circ} \mathrm{C}$ upper limit recommended by the ASHRAE Handbook [16]. The temperature difference between the indoor and outdoor temperatures was $15.1^{\circ} \mathrm{C}$ to $19.1^{\circ} \mathrm{C}$. Therefore, this thermosyphon heat exchanger and the building envelope can dissipate enough heat during a Beijing winter day for the test model data center with a total $1.1 \mathrm{~kW}$ heat load, so there is no need to turn on the air conditioner.

The energy consumed by the thermosyphon heat exchanger, using ambient energy to cool the data center, is only due to the fans, which have a total power consumption of $60 \mathrm{~W}$. The thermosyphon heat exchanger worked continuously throughout these tests, so the total energy consumption of the thermosyphon heat exchanger over 48hours was about $2.88 \mathrm{~kW} \mathrm{~h}$, which was much less than the heat dissipation from the thermosyphon heat exchanger [15]. The energy consumed by the air conditioner over a 48-h period was about $7 \mathrm{~kW} \mathrm{~h}$ as calculated in section 2.2. Thus the energy consumption of the thermosyphon heat exchanger was only about $41 \%$ of that consumed by the air conditioner, giving a $60 \%$ saving. A lower power fan that could still provide the required cooling would further reduce the energy consumption of the thermosyphon heat exchanger. Also, the air conditioner operates differently from the thermosyphon heat exchanger. The air conditioner continuously controls the indoor temperature using an automatic control system. The thermosyphon heat exchanger used here was manually turned on and ran continuously in these tests. A thermosyphon heat exchanger with an automatic control system would be turned on and off to further reduce the energy consumption. The continuous running of the thermosyphon heat exchanger caused the indoor temperature to drop to $12.8^{\circ} \mathrm{C}$, which is much lower than the upper limit of the required indoor temperature. Thus, if the shutoff temperature of the thermosyphon heat exchanger was set to $22^{\circ} \mathrm{C}$ (much higher than $12.8^{\circ} \mathrm{C}$ ) and an automatic control system was used, the working time of the thermosyphon heat exchanger would be greatly reduced. The power con- sumption would then significantly decrease to less than $41 \%$ of the air conditioner, perhaps to as low as $1 / 3$ of the air conditioner power.

The thermosyphon heat exchanger would keep working as long as the outdoor temperature is less than the indoor temperature and the difference between the indoor and the outdoor temperature is more than the start-up temperature difference of the thermosyphon heat exchanger. According to the weather data from the DeST Software, there are $5244 \mathrm{~h}$ each year when the outdoor temperature in Beijing is less than $25^{\circ} \mathrm{C}$ and the difference between the indoor and outdoor temperatures is more than $3^{\circ} \mathrm{C}$, which is thus occurs about $60 \%$ of the year. If the thermosyphon heat exchanger can completely replace the air conditioner for these hours and the energy consumed by the thermosyphon heat exchanger is $41 \%$ of the air conditioner, then the annual energy consumption of the air conditioning system will be reduced by $35.4 \%$.

\subsection{Air conditioner set temperature}

If the air conditioner set temperature is increased, the energy consumed by the air conditioner will decrease for the same working conditions. The 2007 ASHRAE Handbook recommends that the inlet air temperature should be increased to $26.7^{\circ} \mathrm{C}$ from $25^{\circ} \mathrm{C}$. The simulation results show that the annual air conditioner energy consumption will be reduced by $2 \%-3 \%$ in Beijing when the air conditioner temperature increases by $1^{\circ} \mathrm{C}$. Thus, the energy consumption and the thermal dissipation characteristics were studied for different air conditioner temperatures $\left(26^{\circ} \mathrm{C}\right.$ and $\left.27^{\circ} \mathrm{C}\right)$. The test results and the total energy consumed by the air conditioner are listed in Table 1.

The indoor and outdoor temperatures for the different set temperatures $\left(26^{\circ} \mathrm{C}\right.$ and $\left.27^{\circ} \mathrm{C}\right)$ are shown in Figure 6. The indoor temperature is constant as shown in Figure 6, while the outdoor temperature varies. The outdoor temperature fluctuates around $0^{\circ} \mathrm{C}$ in the first test period, while it is more than $0^{\circ} \mathrm{C}$ in the second test period.

The variations in the power consumed by the air conditioner for the different indoor set temperature are shown in Figure 7 . The power consumption changes rapidly, with the total power consumption for the different indoor set temperatures being listed in Table 1.

The total air conditioner energy consumption for the 46-h test period ranges from 8.0 to $9.0 \mathrm{~kW} \mathrm{~h}$ as shown in Table 1, with an average energy consumption of 4 to $5 \mathrm{~kW}$ h for a 24-h period. Thus, when the set temperature is increased by $1^{\circ} \mathrm{C}$ from $26^{\circ} \mathrm{C}$ to $27^{\circ} \mathrm{C}$, the total energy consumed by the air conditioner increases by $1.83 \%$, even though the indoor set temperature is higher. The total energy consumption increases for the higher indoor temperature because the outdoor temperature varies during the test. The higher outdoor temperature will reduce the heat dissipation through the building envelope. The air conditioner thermal 
Table 1 Total air conditioner energy consumption for different indoor set temperatures

\begin{tabular}{cccc}
\hline $\begin{array}{c}\text { Indoor set } \\
\text { temperature }\end{array}$ & Start time & Stop time & $\begin{array}{c}\text { Total energy con- } \\
\text { sumption }(\mathrm{kW} \mathrm{h})\end{array}$ \\
\hline $26^{\circ} \mathrm{C}$ & 2009.11 .21 & 2009.11 .23 & 8.5 \\
& $22: 51$ & $20: 51$ & \\
$27^{\circ} \mathrm{C}$ & 2009.11 .25 & 2009.11 .27 & 8.7 \\
\hline
\end{tabular}
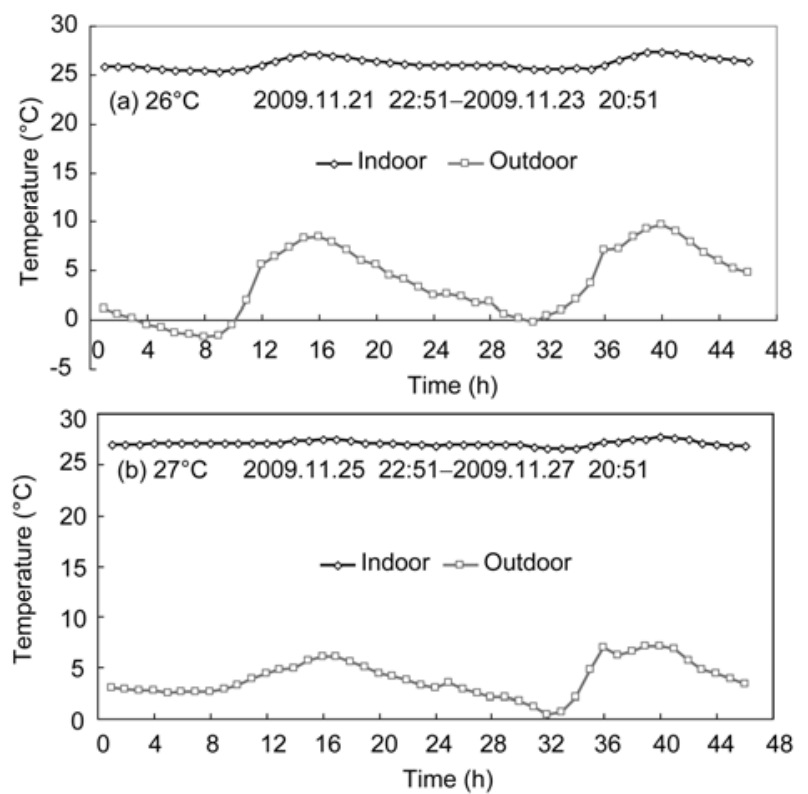

Figure 6 Indoor and outdoor temperatures with the air conditioner for different indoor temperature.

load will then increase even though the total thermal load remains constant. Thus, even though the air conditioner thermal load may decrease with the increasing indoor temperature, the outdoor temperature has a significant effect on energy consumption.

\subsection{Outdoor temperature and air conditioner energy consumption}

The tests show that the outdoor temperature has a greater effect than the air conditioner set temperature on the air conditioner energy consumption. Figure 8 shows the variations of the outdoor temperature for two different time periods from Nov. 15, 2009 to Nov. 17, 2009 and from Nov. 17, 2009 to Nov. 19, 2009. The air conditioner temperature is set at $25^{\circ} \mathrm{C}$ in both test periods.

The outdoor temperature is almost the same after the 30th hour for both test periods as shown in Figure 8. However, the outdoor temperature in the first period is lower than that in the second period during the first $30 \mathrm{~h}$. Thus, the heat dissipation through the building envelope in the first test period is higher than that in the second test period, so the air conditioner energy consumption in the first test period is lower than that in the second test period. The total air conditioner energy consumption is $6.836 \mathrm{~kW} \mathrm{~h}$ in the
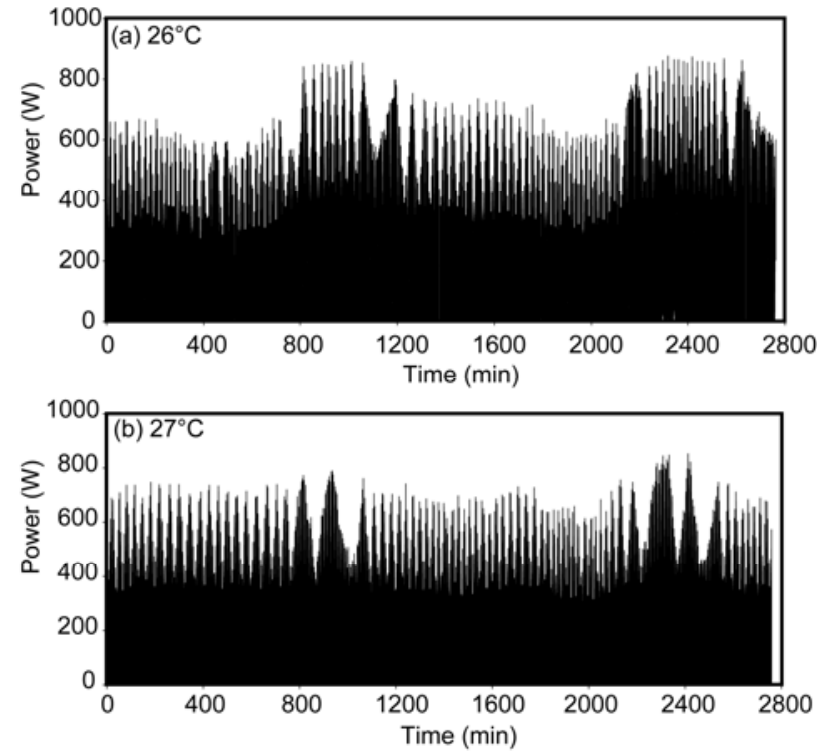

Figure 7 An air conditioner power consumption for different indoor temperature.

first test and $7.634 \mathrm{~kW} \mathrm{~h}$ in the second test. Thus, the energy consumption increases by $11.7 \%$. The average outdoor temperature is about $-0.1^{\circ} \mathrm{C}$ in the first test period and about $1.6^{\circ} \mathrm{C}$ in the second test period as shown in Figure 8 , giving a temperature difference of less than $2^{\circ} \mathrm{C}$. Thus, the air conditioner energy consumption increases by $5 \%-6 \%$ when the outdoor temperature increases by $1^{\circ} \mathrm{C}$.

\section{Conclusions}

Considering the various energy management strategies proposed for data centers, the use of ambient energy to cool the data center with a thermosyphon heat exchanger may be the most effective because it significantly reduces the air conditioner's running time while keeping the indoor and outdoor air totally separate, and also maintaining the humidity and cleanliness of the data center. The heat dissipation characteristics and the energy consumption of a thermosyphon heat exchanger and an air conditioner for a typical data center were investigated. The heat dissipation through the

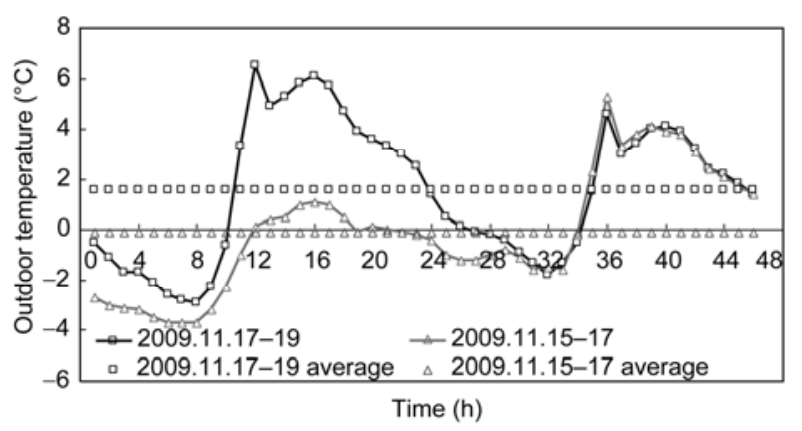

Figure 8 Outdoor temperatures during two different tests. 
building envelope was also measured. The data showed that:

(1) The heat dissipation required by the data center cannot only be provided by heat transfer through the building envelope in Beijing during the winter.

(2) The heat transfer through the building envelope for the test conditions was about $19.5 \%$ of the total thermal load. The average energy consumed by the air conditioner was 4 to $5 \mathrm{~kW}$ h over a 24 -h period depending on the outdoor temperature.

(3) The average temperature difference between the indoor and outdoor temperatures using the thermosyphon heat exchanger was less than $20^{\circ} \mathrm{C}$ and the energy consumed by the thermosyphon heat exchanger was only $41 \%$ of that of the air conditioner. Thus, the annual energy consumption could be reduced by $35.4 \%$.

(4) The outdoor temperature had a greater effect than the indoor set temperature on the air conditioner energy consumption. The energy consumed by the air conditioner increased by $5 \%-6 \%$ on average for an outdoor temperature increase of $1^{\circ} \mathrm{C}$.

This work was supported by the National Natural Science Foundation of China (51076003), the Specialized Research Fund for the Doctoral Program of Higher Education (200800050010), and the Innovation Program for the Doctoral Students of Beijing University of Technology (bcx-2009049).

1 Jonathan G K. Estimating total power consumption by servers in the U. S. and the world. Oakland, CA: Analytics Press. 2007, 2, http:// enterprise.amd.com/us-en/AMD-Business/Technology-Home/PowerManagement.aspx

2 Vincent M. Preventing a data center power crisis. 2009, http:// searchdatacenter.techtarget.com/tip/0,289483,sid80_gci1350324_me$\mathrm{m} 1,00 . \mathrm{html}$

3 Iyengar M, Schmidt R. Analytical modeling for thermodynamic characterization of data center cooling systems. J Elect Packaging,
2009, 131: 021009-1-9

4 Chandrakant D P, Cullen E B, Christian B. Computational fluid dynamic modeling of high compute density data centers to assure system inlet air specifications. In: Proceedings of IPACK'01, The Pacific Rim/ASME International Electronic Packaging Technical Conference and Exhibition, Kauai, Hawaii, USA, 2001, IPACK2001-15622

5 Udakeri R, Mulay V, Agonafer D. Comparison of overhead supply and underfloor supply with rear heat exchanger in high density data center clusters. In: Proceedings of 24th Annual IEEE Semiconductor Thermal Measurement and Management Symposium, San Jose, CA, 2008, IEEE, 166-173

6 Cho J, Lim T, Kim B S. Measurements and predictions of the air distribution systems in high compute density (Internet) data centers. Energy Buildings, 2009, 41: 1107-1115

7 Mark F. Data center energy a concern, but metrics lacking. 2008, http://searchdatacenter.techtarget.com/news/article/0,289142,sid80_g ci1329440,00.html

8 Jinkyun C, Taisub L, Byungseon S K. Cooling systems for IT environment heat removal in (internet) data centers. J Asian Archit Building Eng, 2008, 7: 387-394

9 Kumar A, Joshi Y. Use of airside economizer for data center thermal management. In: Proceedings of 2nd International Conference on Thermal Issues in Emerging Technologies, Cairo, Egypt, 2008, IEEE, $57-66$

10 Li J R, Yang L. Numerical simulation of fresh air exchanger effecting indoor environment. J Harbin Univ Sci Tech, 2009. 14: 127-130

11 Chen Y, Wu J, Wang F. Study on ventilation cooling technology for telecommunication base stations in Guangzhou. Building Sci, 2008, 24: $27-31$

12 Bao L L, Wang J G, Zhang M J. Performance test and analysis on the air heat exchanger used in communication equipment plant. Refrig Air Condi Electric Power Mach, 2008, 29: 70-73

13 Shehabi A. Energy implications of economizer use in california data centers. Lawrence Berkeley National Laboratory, 2008, http://eschola rship.org/uc/item/4px2n6jn

14 EPA. U. S. Environmental Protection Agency ENERGY STAR Program. Report to Congress on Server and Data Center Energy Efficiency Public Law 109-431, 2007

15 Zhou F, Ma G Y. Experiment of characteristics of thermosiphon heat recovery equipment under summer condition. HV\&AC, 2007, 372: $58-62$

16 ASHRAE. 2007 ASHRAE Handbook-HVAC Applications. Chapter Atlanta: American Society of Heating, Refrigerating and Air-Conditioning Engineers, Inc, 2007

Open Access This article is distributed under the terms of the Creative Commons Attribution License which permits any use, distribution, and reproduction in any medium, provided the original author(s) and source are credited. 